\title{
PISO PRODUZIDO A PARTIR DE FIBRAS VEGETAIS
}

\author{
Floor Produced From Plant Fibers
}

ISSN: 1984-3151

\author{
Artur Welerson Lopes dos Santos*1; Isabela Valadares Lima'; Izabel Braz Ferreira de \\ Souza ${ }^{1}$; Júlia Duarte Francisco ${ }^{1}$; Paula de Araújo Franco1; Poliana Francisco de Oliveira ${ }^{1}$; \\ Sheila Cassiane Rosa da Silva ${ }^{1}$; Thadeu Nascimento Valério ${ }^{1}$; Arlete Vieira da Silva ${ }^{2}$ \\ (Orientadora)
}

\footnotetext{
1 Alunos de Graduação em Engenharia Civil do Centro Universitário de Belo Horizonte - UniBH. Belo Horizonte, MG. *arturwelerson@hotmail.com.

2 Mestre em Geografia e Análise Ambiental. IGC/UFMG, 2002. Professora do Centro Universitário de Belo Horizonte - UniBH. Belo Horizonte, MG - arlete.silva@prof.unibh.br.
}

Recebido em: 08/09/2011 - Aprovado em: 08/10/2011 - Disponibilizado em: 13/10/2011

RESUMO: Este artigo apresenta um estudo relacionado ao uso das fibras vegetais na produção de um piso ecológico, objetivando confeccioná-lo a partir das fibras de coco seco. Como metodologia utilizou-se a pesquisa experimental. Nesse contexto, foram produzidos pisos para análise de resistência, tendo como componentes, a mistura de resina e fibras de coco seco. O piso confeccionado apresentou resultados positivos e, diante disso, pode-se afirmar que o desenvolvimento sustentável dessa produção tem benefícios para a sociedade, o meio ambiente e o meio acadêmico.

PALAVRAS-CHAVE: Fibras de coco seco. Sustentabilidade. Meio Ambiente.

ABSTRACT: This article presents a study related to the use of vegetable fibers in the production of an ecological floor, aiming confection it from coconut fibers. The methodology used the experimental research. In this context, floors were produced for analysis of resistance, with the components, the mixture of resin and fibers of coconut. The floor made positive results and, before that, it can be said that sustainable development of this production has benefits for society, environment and academia.

KEYWORDS: Coconut fibers. Sustainability. Environment.

\section{INTRODUÇÃO}

A noção de desenvolvimento sustentável tem sido largamente utilizada nas teorias de conservação e preservação do meio ambiente e em toda sociedade, portanto, conforme afirma a Resolução CNE/CES n. ${ }^{011 / 2002, ~ o ~ e n g e n h e i r o ~ d e v e ~ t e r ~ u m a ~ a t u a c ̧ a ̃ o ~ c r i ́ t i c a ~}$ e criativa na identificação e resolução de problemas, considerando seus aspectos políticos, econômicos, sociais, ambientais e culturais, com visão ética e humanística, em atendimento às demandas da sociedade (BRASIL, 2002)

Este artigo apresenta um estudo relacionado à contribuição das fibras vegetais para a fabricação de piso a partir de fibras de coco seco, visando o desenvolvimento sustentável, ou seja, aquele capaz de suprir as necessidades da geração atual, sem comprometer a capacidade de atender as futuras gerações. 
No mundo globalizado, ocorre a tensão entre gerações presentes e futuras e o meio ambiente, sendo, pois, necessária a conscientização para manter um equilíbrio ambiental. Assim, o reaproveitamento dos recursos naturais torna-se uma tentativa de utilizar matéria prima para a produção de um piso ecologicamente correto e não proporcione nenhum tipo de degradação ambiental.

Diante da necessidade mundial de promover a sustentabilidade, tem-se observado uma preocupação crescente por partes das empresas no sentido de utilizar produtos econômicos e métodos inovadores, buscando causar menos impacto ao meio ambiente.

O aproveitamento das fibras de coco seca, na utilização de novos produtos, tem conquistado um espaço significativo no mercado, pois apresentam a mesma qualidade, resistência e durabilidade dos tradicionais e, em alguns casos, chegam a custar $40 \%$ menos.

À luz dessas reflexões, considerou-se o uso das fibras de coco seco um fator fundamental para atender a sustentabilidade e o meio ambiente, pois ao fazer uso das fibras, reduz-se a quantidade de resíduos e contribui-se para a preservação ambiental, visto que não há necessidade de degradar o meio ambiente para obter a matéria prima.

Com base no exposto, este projeto tem como objetivo, confeccionar um piso a partir de fibras de coco seco, de baixo custo e ecológico, já que essas fibras são encontradas com grande facilidade nas cidades, devido ao consumo de água de coco em locais como, praias e feiras e outros.

\section{REFERENCIAL TEÓRICO}

\subsection{SKATBOARD FOLHA SECA}

Segundo Berttoldo (2008), o projeto folha seca foi desenvolvido pela empresa Fibra Design Sustentável, no qual o desafio era desenvolver um produto fabricado com materiais brasileiros, inserido em uma cadeia de produção sustentável. "Segundo a Empresa Fibra Desing, a elaboração do Skate poderia proporcionar uma maneira alternativa e empírica de realizar testes físicos e mecânicos do material”. Para a fabricação do skate foi usado plantas como as palmáceas, gramíneas, bromélias entre outras. Tanto o material, quanto ao produto foram premiados e tiveram grande repercussão na mídia e em exposições nacionais e internacionais. (FIBRA DESIGN SUSTENTAVEL, 2010, p. 1).

\subsection{UtILIZAÇõES DE FIBRAS VEgETAIS PARA REFORÇO DE PLÁSTICOS}

A utilização de fibras sintéticas para o reforço de plásticos e borrachas (polímeros) é uma técnica extensivamente empregada na indústria para a obtenção de materiais com melhor desempenho mecânico. A substituição de fibras sintéticas por fibras vegetais é comercial e ambientalmente mais viável, pelo fato de terem fonte renovável, serem biodegradáveis, de baixo custo e por provocarem menor impacto ambiental (MATTOSO et al., 1996).

As fibras vegetais ou lignocelulósicas possuem menor densidade e provocam desgaste inferior ao das sintéticas nos equipamentos convencionais de processamento de polímeros. Além disso, o Brasil é, sem dúvida, um dos países que possuem a maior biomassa do mundo e a maior extensão territorial cultivável, potenciais estes que devem ser mais bem explorado. (MATTOSO et al.,1996) 
Segundo os mesmos autores, entre as fibras vegetais que podem ser utilizadas para esta aplicação estão: sisal, rami, juta, malva, curauá e fibra de coco. A fibra de sisal se destaca entre as fibras foliares, em termos de qualidade e de aplicação comercial e, também, por possuir um dos maiores valores de módulo de elasticidade. No Brasil a utilização de fibras vegetais na indústria automobilística e de construção civil está tomando novo impulso, embora as técnicas de fabricação desses compósitos ainda sejam incipientes, demoradas e pouco produtivas.

Fibras vegetais já foram largamente empregadas no passado na indústria automobilística, segundo (MARROQUIM, 1994 apud MATTOSO et al.,1996). Como foi o caso de compósitos de látex de borracha natural reforçado com fibra de coco para uso em estofamentos de automóveis.

No entanto, a partir da década de 60 estas começaram a ser gradativamente substituídos pelas espumas de poliuretano. A fibra vegetal apresenta maior perspirabilidade (capacidade de absorver umidade da transpiração humana), o que proporciona maior conforto, essencial para os motoristas profissionais de táxi, ônibus e caminhões, que ficam longos períodos de tempo sentados. A geração de empregos rurais e industriais é outro aspecto importante do uso de fibras vegetais. Um assento de carro com fibra vegetal utiliza pelo menos quatro vezes mais mão-de-obra do que o feito de espuma (MARROQUIM, 1994 apud MATTOSO et al.,1996).

Ainda hoje, veículos de primeira linha de empresas no exterior, tais como a Mercedes Benz da Alemanha, utilizam estofamentos com fibras vegetais. Outra grande vantagem do uso de fibras vegetais é a sua não toxidez. (MATTOSO et al.,1996)

De acordo com os mesmos autores atualmente, as indústrias automotivas e de plásticos estão recuperando o interesse em fibras vegetais, devido suas vantagens para a substituição de fibras inorgânicas/minerais, tais como a fibra de vidro, comumente utilizada na indústria em formulação com diferentes resinas, plásticos e borrachas, na substituição de placas de madeira ou em formulação com argamassa.

\subsection{USOS DE RESíDUOS DE FIBRA VEGETAL EM CONSTRUÇÃO}

As principais finalidades de se reforçar a matriz frágil com fibras são o aumento das resistências à tração e ao impacto, a maior capacidade de absorção de energia e a possibilidade de uso no estágio pósfissurado. (COUTTS, 2005 apud SAVASTANO JÚNIOR; SANTOS, 2008).

Os mesmos autores ressaltam que o tipo, a distribuição, a relação comprimento-diâmetro e a durabilidade da fibra, assim como o seu grau de aderência com a matriz, determinam o comportamento mecânico do compósito e o desempenho do componente.

Ainda os mesmos autores afirmam que o uso de fibrocimentos que utilizam polpa celulósica como reforço, tem sido consagrado, graças a constantes aperfeiçoamentos de matérias-primas, processos produtivos com consumo racionalizado de energia e custos de investimento cada vez menores.

\section{Metodologia}

Segundo GIL (2002), esta pesquisa é de natureza experimental. Pois, consiste em determinar um objeto de estudo, selecionar as variáveis que seriam capazes de influenciá-lo, definir as formas de controle de observação dos efeitos que as variáveis produzem no objeto.

Os procedimentos metodológicos consistiram em realizar um levantamento bibliográfico para permitir um nivelamento do conhecimento do grupo de 
pesquisadores e dar embasamento na discussão dos resultados.

O processo de obtenção de fibra de coco inicia na secagem das fibras. Atividade que se prolongou por sete dias de exposição ao sol.

A etapa seguinte consiste em preparar o molde para o piso, que foi criado um tabuleiro de metal.

O piso foi desenvolvido utilizando fibra de coco seco desfiado, misturado com Resina Poliéster Isoftálica e Catalisador para que ocorra o processo de secagem.

\section{DemonstraçÃo dos RESULTADOS}

Inicialmente para a confecção do piso as fibras de coco ficaram expostas ao sol por sete dias e após sua secagem, as fibras foram desfiadas e adicionadas à mistura de resina isoftálica e catalisador. A mistura foi distribuída em uma forma e exposta ao sol para haver a reação da resina com as fibras, para dar origem ao piso, como observado na FIG.1.

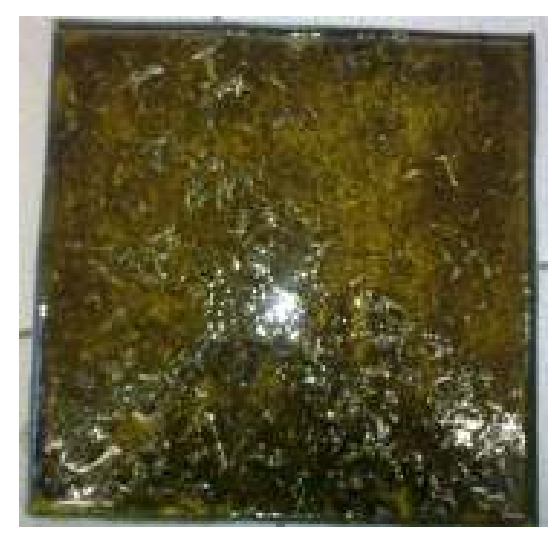

Figura 1 - Detalhe do Piso confeccionado a partir de fibra de coco seco.

Para os testes de resistências foram realizados os seguintes experimentos:

- O piso foi mergulhado em cloro, água sanitária e sabão em pó, a fim de verificar se o piso se desfragmentaria, não ocorrendo nenhuma reação em sua composição.
- Colocou-se um peso de aproximadamente $80 \mathrm{Kg}$, para verificar se o piso suportaria a compressão dessa força sem que ocorra nenhuma alteração em sua forma.

Conseguiu-se, assim, que fosse feito um piso resistente e bonito ao mesmo tempo, para sucesso do objetivo da pesquisa.

\section{CONCLUSÃo}

O tema estudado nesse trabalho é a conciliação do uso de recursos naturais eficazes e econômicos no âmbito da construção civil, com a preocupação constante e a tentativa de buscar o uso de tais recursos sem degradar a natureza, o que se pode chamar de sustentabilidade. Quando utilizadas as fibras de coco seco, não há a necessidade da colheita desordenada da fruta, pois existe um consumo de água de coco significativo no mercado, acumulandose um excesso de resíduos. Que, ao serem jogados na natureza, causam sérios problemas ambientais.

As fibras têm grande utilidade comercial. Podem ser utilizadas de diversas maneiras no ramo industrial e no artesanato, aceitas pelo mercado, substituindo, com vantagens, como é o caso do estofamento de bancos de veículos e tapetes.

Em outros campos do conhecimento, verifica-se que diversos experimentos têm sido utilizados $e$ publicados. Feiras de exposição, noticiários, internet $\mathrm{e}$ trabalhos científicos mostram o uso desse recurso na decoração de interiores, em painéis para jardins, confecções de bijuterias, redes para descanso, chapéus, em prancha de skatboard e outros. Diante desses bons resultados já obtidos pelos decoradores, profissionais do ramo da jardinagem, no artesanato e nas indústrias, afirma-se é possível produzir piso a partir de fibras de coco seco.

A utilização de fibras vegetais vem crescendo em vários setores, tais como automobilístico, artesanal, 
industrial de construções, tendo uma aceitação considerável no mercado. Pois ao utilizar as fibras vegetais, reaproveitam-se os meios naturais, porém sem causar danos ao meio ambiente visando a sustentabilidade.

Portanto, conclui-se que há uma relação muito forte entre o meio ambiente e a construção civil, se o engenheiro for adepto ao reaproveitamento de recursos naturais e ser comprometido com o desenvolvimento de estudos e pesquisas, criando uma relação sustentável capaz de permanecer nas futuras gerações.

\section{CONSIDERAÇÕES FinAIS}

Um dos propósitos deste trabalho é enfatizar a responsabilidade do ser humano em relação ao meio ambiente e à natureza.

Diante do experimento inicial, procurou-se aprofundar em pesquisa experimental, a fim de testar a durabilidade e a resistência do piso feito com fibra de coco seco, quando exposto em ambiente doméstico, em contato direto com produtos químicos de limpeza diária. Sendo aprovado nesses testes, acredita-se que o piso poderá trazer grandes benefícios à sociedade e ao meio ambiente.

\section{REFERÊNCIAS}

BERTTOLDO, Sanny. Ecologicamente Correto: Skate Board. Rio de Janeiro: O Globo, 2008. Disponível em: http://www.fibradesign.net/imprensa/imagem/pdf/o globo_esportes.pdf Acesso em: 13. nov. 2010.

BRASIL. Resolução CNE/CES $n^{\circ}$. 11/2002: institui diretrizes curriculares nacionais do Curso de Graduação em Engenharia. Brasília/DF: D.O.U., 2002. art. $3^{\circ}$ e $4^{\circ}$. Seção 1. p. 32. Disponível em: http://portal.mec.gov.br/cne/arquivos/pdf/CES112002.p df. Acesso em: 17. mai. 2011.

FIBRA DESIGN SUSTENTAVEL. Fibra Rewind: Mega Rampa. Rio de Janeiro/RJ: FIBRA DESIGN SUSTENTAVEL, 2010. p. 1. Disponível em: http://www.fibradesign.net/blog/categoria.php?cat=3 Acesso em: 13. nov. 2010.
GIL, Antonio Carlos. Como Elaborar Projetos de Pesquisa. 4ª ed. São Paulo: Atlas; 2002.

MATTOSO, Luiz Henrique Caparelli et al. Utilização de fibras vegetais para reforço de plásticos. São PauloSP: EMRAPA, 1996. p. 1-4. n.3. Disponível em: www.cnpdia.embrapa.br/publicacoes/download.php Acesso em: 29 out. 2010.

SAVASTANO JUNIOR, Holmer; SANTOS, Sérgio dos. O Uso de Resíduos de Fibra Vegetal em Construção. Revista Eletrônica de Jornalismo, Com Ciência. São Paulo/SP: Com Ciência, 2008. p.1. n.95. SP. Disponível em: http://www.comciencia.br/comciencia/?section=8\&edic ao=32\&id=382 Acesso em: 12 nov. 2010. 